of water, which is generally the case when the task is intrusted to a subordinate, it is sometimes next to impossible to concentrate the fluid enough to show the results with the desired plainness.

"Returning home, we poured the fluid into soup-plates set on a table before a window. The diatoms speedily settled on the sides and bottoms of the plates, coating them with a green slime, the thickness and tint of which varied with the proportion of diatoms present. In each plate, according to its size, we put three to six perfectly white oysters which had never been in the 'clears,' and the shells of which had previously been washed and brushed clean. In similar plates like numbers of the same oysters were laid in ordinary sea water. Twenty-six hours after the commencement of the experiment the oysters in the water charged with diatoms had all acquired a marked greenish hue; the other oysters remained unaltered. The experiment was repeated many times with identically the same results. The green colour in the oysters was found to be more decided in proportion as the water was more highly charged with diatoms. In the course of the experiments the shell of one of the oysters was perforated, so as to lay bare the mantle. After the oyster had turned green, it was laid in ordinary sea-water for a few days, when the greenness disappeared altogether. It reappeared when the oyster was replaced in fresh water containing Navicula ostrearia. The experiment was repeated, with like results, in the laboratory of M. Decaisne, Jardin des Plantes, Paris, to which a supply of white oysters and sealed flasks of the water containing the diatoms was forwarded.

"In the course of the experiments it was observed that by the opening and closing of their valves the oysters induced currents in the water, by means of which they drew towards them and surrounded themselves with the particles of matter suspended therein. The existence and direction of these currents were shown by the disappearance of the slime and the consequent laying bare of the sides and bottoms of the plates, the diatoms remaining only at points out of reach of the currents.

"Directed towards the buccal aperture by the cilia with which the branchiæ are provided, the naviculæ enter the stomach of the mollusc, and there part with their nutritive constituents. The yellow chlorophyll is digested and decomposed; the soluble colouring matter passes direct into the blood, to which it imparts its colour. Thus it happens that the most vesicular portions of the structure, as the branchiæ, are the most highly coloured.

"Examination of the digestive tubes of the oysters experimented upon proved the fact of the absorption of the diatoms. The stomachs, intestines, and exuviæ were strewed with carapaces of naviculæ. The carapaces, being siliceous, are not affected by the digestive juices, and it would seem extraordinary that with so tenacious a covering their contents should be evolved, were it not for the knowledge of the fact that the covering is not continuous, the line of suture separating the valves composing the frustule being scarcely silicified at all."

It would therefore appear to be established beyond dispute that the green hue in oysters is due exclusively to their absorption of certain naviculæe contained in the circumambient water. The facts are in perfect keeping with the observations of growers that heavy rains (which increase the supply of fresh water) cause the disappearance of the green from the "clears," while, on the other band, dry north-east gales, which greatly increase the saturation of the water, bring it, as it is called, "into condition."

Two points of special interest in connection with the subject remain for future investigation. These are :-

1. Does the navicula in question remain all the year in the waters where it is found in winter?

2. Is the coloration of the beds accidental or temporary? -in other words, does this alga disappear from the reservoirs when the water changes its colour, or does it become itself discoloured for a time?

H. M. C.

\section{MODERN ENTOMOLOGY}

$\mathrm{T}^{\mathrm{T}}$ is the good fortune of your president on this occasion to welcome you to his native heath, where our favourite science has been longer, more uninterruptedly, and perhaps more zealously cultivated than anywhere else in the New World. Here, in the last century, Peck studied the Canker-worm and the

x Annual Address before the Entomological Club of the American Associa tion for the Advancement of Science, by the President, Mr. S. H. Scudder, of Cambridge.
Slug-worm of the Cherry, and in late years Rhynchonus, Stenocorus, and Cossus-all highly destructive insects. Here lived Harris, who cultivated entomology in its broadest sense, and whose classic treatise was the first important Government publication on injurious insects. Here to-day we have two associations for our work, consisting, it will be confessed, of nearly the same individuals, and not many of them, but meeting frequently -one in Boston, the other in Cambridge. Harvard acknowledges the claims of our study in supporting not only an instructor in entomology at its Agriculturad School, but a full Professor of the same in the University at large.

In our own day the spreading territory of the United States, the penetration of its wilds, and the inersection of its whole area by routes of travel, the wider distribution and greatlyincreased numbers of local entomologists, as well as the demand for our natural products abroad, have set before us temptation to study only new forms and to cultivate descriptive work, to the neglect of the choicer, broader fields of our ever-opening science. It is this danger to which I venture briefly to call your attention to-day, not by way of disparaging the former, but rather in the hope that some of our younger members, who have not yet fallen into the ruts of work, may be induced to turn their attention to some of the more fruitful fields of diligent research.

We should not apply the term descriptive work merely to the study of the external features of insects. The great bulk of what passes for comparative anatomy, physiology, and embryology is purely descriptive, and is only to be awarded a higher grade in a scale of studies than that which deals with the external properties when it requires a better training of the hand and eye to carry it out, and greater patience of investigation. We pass at once to a higher grade of research when we deal with comparisons or processes (which of course involve comparisons). All good descriptive work indeed is also comparative; but at the best it is so only in the narrowest sense, for only intimately allied forms are compared. In descriptive work we deal with simple facts; in comparative work we deal with their collocation. "Facts," said Agassiz one day, "facti ar stupid things, until brought in connection with some general law."

It is to this higher plane that concerns itself with general laws that I would urge the young student to bend his steps. The way is hard; but in this lies one of its charms, for labour is its own reward. It is by patient plodding that the goal is reached; every step costs and counts; the ever-broadening field of knowledge exhilarates the spirit and intensifies the ambition; there is no such thing as satiety-study of this sort never palls.

It is hardly necessary to point out that so-called systematic work never reaches this higher grade unless it is monographic unless it deals in a broad way with the relationship and general affinities of insects. It is not my purpose to call attention here to the needs of science in this department, as they are too patent to escape observation; but if one desires a model upon which to construct such work, one need not look further than the "Revision of the Rhynchophora," by Drs. LeConte and Horn. Rather than linger here we prefer to pass directly to some of the obscurer fields of study.

When we compare the number of insect embryologists in America with that of their European colleagues, the result is somewhat disheartening and discreditable; although perhaps the comparison would be not quite so disproportionate were some of our students to publish their notes. But take all that has been done upon both sides of the water, and what a meagre showing it makes! Of how many families of Coleoptera alone have we the embryonic history of a single species?

In following the post-embryonal history of insects there is work for all. While allied forms have in general a very similar development, there are so many which are unexpectedly found to differ from one another, that every addition to our knowledge of the life histories of insects is a gain, and they are to be praised who give their close attention to this matter. Here is a field any entomologist, even the most unskilled, may cultivate to his own advantage and with the assuance that every new history he works out is a distinct addition to the science. The importance of an accumulation of facts in this field can hardly be overestimated, and those whose opportunities for field-work are good should especially take this suggestion to heart. Nor, by any means, is the work confined to the mere collection of facts. How to account for this extraordinary diversity of life and habits among insects, and what its meaning may be, is one of the problems of the evolutionist. There are also here some specially curious inquiries, to which Sir John Lubbock and 
others have recently called attention, and to which Mr. Riley has contributed by his history of Epicauta and other Meloida. I refer to the questions connected with so-called hypermetamorphosis in insects. In these cases there are changes of form during the larval period greater than exist between larva and pupa, or even between larva and imago, in some insects. There are also slighter changes than these which very many larva undergo ; indeed it may safely be asserted that the newlyhatched and the mature larvæ of all external feeders differ from each other in some important features. The differences are really great (when compared to th $\sigma$ differences between genera of the same family at a similar time of life) in all lepidopterous larvæ, as well as in all Orthoptera which have come under my notice. No attempt to co-ordinate these differences, or to study their meanings, or to show the nature of their evident relationship to hypermetamorphosis has ever been attempted.

Not less inviting is the boundless region of investigation into the habits of insects and their relation to their environment. The impulse given to these studies by the rise of Darwinism, and the sudden and curious importance they have assumed in later investigations into the origin and kinship of insects, need only to be mentioned to be acknowledged at once by all of you. The variation in coloration and form exhibited by the same insect at different seasons or in different stations, "sports," the phenomena of dimorphism, and that world of differences between the sexes, bearing no direct relation to sexuality; mimicry also, phosphorescence and its relations to life, the odours of insects, the relation of anthophilous insects to the colours and fructification of flowers, the modes of communication between members of communities, the range and action of the senses, ${ }^{1}$ language, commensalism-these are simply a few topics selected quite at random from hundreds which might be suggested, in each of which new observations and comparative studies are urgently demanded.

The fundamental principles of the morphology of insects were laid down by Savigny in some memorable memoirs more than sixty years ago; the contributions of no single author since that time have added so much to our knowledge, notwithstanding the aid that embryology has been able to bring. Nevertheless there remain many unsolved problems in insect morphology which by their nature are little likely to receive help from this source. Let me mention three :-

The first concerns the structure of the organs of flight. The very nomenclature of the veins shows the disgraceful condition of our philosophy of these parts; the same terminology is not employed in any two of the larger sub-orders of insects ; names without number have been proposed, rarely however by any author with a view to their applicability to any group outside that which formed his special study; and a tabular view which should illustrate them all would be a curious sight. A careful study of the main and subordinate veins, their relations to each other, to the different regions of the wing, to the supporting parts of the thorax and to the alar muscles, should be carried through the entire order of insects; by no means, either, neglecting their development in time, and possibly deriving some assistance in working out homologies by the study of their hypodermic development.

The second concerns the mouth parts. The general homologies of these organs were clearly and accurately enough stated by Savigny, though one may perhaps have a right to consider the last word not yet said when one recalls Saussure's recent claim to have found in Hemimerus a second labium. What I refer to, however, is another point : it relates to the appendages of the maxillæ and the labium. Considering the labium as a soldered pair of secondary maxillæ, we have at the most, on either pair of maxillæ, three appendages upon either side. These appendages, as you know, are very variously developed in different sub-orders of insects, or even in the same sub-order; and it has at least not been shown, and I question if it can be done, that the parts bearing similar names in different sub-orders are always homologous organs. Here is a study as broad and perhaps as difficult as the last.

The third is the morphological significance of monstrosities, especially of such as are termed monstrosities by excess. The literature of the subject is very scattered, and the material much more extensive than many of you may think. At present this subject is, so to speak, only one of the curiosities of entomology, but we may be confident that it will one day show important relations to the story of life.

I Notice Meyer's beautiful studies on the perception of sound by the mosquito.
After all the labours of Herold, Treviranus, Lyonet, Dufour, and dozens of other such industrious and illustrious workers, is there anything important remaining to be done in the gros anatomy of insects? some of you would perhaps ask. Let the recent work of some of our own number answer, which has shown in the Hemiptera and Lepidoptera the existence of a curious pumping arrangement by which nutritious fluids are forced into the stomach. It is certainly strange that after all that has been said as to the mode in which a butterfly feeds, no one should have dissected a specimen with sufficient care to have seen the pharyngeal sac which Mr. Burgess will soon show us. No! the field is still an open one, as the annual reviews clearly show. The curious results of Flögel's studies of the brain, the oddly constructed sense-organs found by Graber and Meyer (earlier noticed briefly by Leydig) in the antennæ of Diptera, the important anatomical distinctions discovered by Forel in different groups of ants, the strange modification of the tip of the spiral tongue in Ophideres, which Darwin, Brietenbach, and Künckel have discussed, and, above all, the extensive investigations of the nervous system in insects generally which Brandt has recently undertaken, the exquisite memoir of Grenacher on the structure of the compound eye, and the keen researches of Graber in various departments of insect anatomy, show by what has been accomplished how many harvests are still unreaped. The microtome, too, has put a new instrument of precision into the hands of the investigator in the field.

If these few words shall arouse in any one a higher ambition, leading to better work, their aim will have been accomplished.

\section{SCIENTIFIC SERIALS}

American Naturalist, August 1880.-D. P. Penhallow, the fabrication of Aino cloth.-H. D. Minot, English birds compared with American.-J. S. Gardner, on the age of the Laramie formation as indicated by its vegetable remains. $-J$. E. Todd, on the flowering of Saxifraga sarmentosa.-Prof. A. N. Prentiss, distribution of obnoxious insects by means of fungoid growths.-Recent literature.-General notes.-Scientific news.

September.-J. Walter Fewkes, the Siphonophores :-No. I, the anatomy and development of Agalma.-Prof. A. N. Prentiss, destruction of obnoxious insects by means of fungoid growths (concluded); the result of these experiments would seem to indicate plainly that yeast cannot be regarded as a reliable remedy against such insects as commonly affect plants cultivated in greenhouses or in windows, but the general question is by no means as yet decided.-O. B. Johnson, birds of the Willamette Valley, Oregon (concluded).-C. O. Whitman, Do flying-fish fly?

Annalen der Physik und Chemie, No. 8.-On electric expansion (continued), by G. Quincke.-Clausius' law and the motion of the earth in space, by E. Budde.-On the dependence of the electric conductivity of carbon on the temperature, by.W. Siemens. - On the phenomena in Geissler tubes under external action, by E. Reitlinger and A. v. Urbanitzky.-Complete theory of the bifilar-magnetometer and new methods of determining the absolute horizontal intensity of the earth's magnetism, as also the temperature and induction coefficients of magnets, by H. Wild.-On the comparison of the electrodynamic fundamental law with experience, by R. Clausius.-On a direct transformation of the vibrations of radiant heat into electricity, by W. Hankel.-On fluorescence, by $\mathrm{E}_{\text {. Lommel. }}$-On the behaviour of different heat rays in the reflection of polarised rays from metals, by $\mathrm{H}$. Knoblauch. - Remark on the heat conductivity of mercury, by $\mathrm{H}$. Herwig.--Remarks on H. Weber's memoir on heat-conduction in liquids, by $\mathbf{A}$. Winkelmann.-On air-resistance, by G. Recknagel.- - On the action of hollow, in comparison with that of solid, steel magnets, by W. Holtz.

No. 9.-On the compressibility of gases, by F. Roth.-On the electric conductivity of some salt solutions, by J. H. Long. - New experimental researches on fluorescence, by $\mathrm{O}$. Lubarsch. -On constants of refraction, by L. Lorenz, -Experimental researches on refraction constants, by $\mathrm{K}$. Prytz.-Theory of reflection and refraction at the limit of homogeneous, isotropic, transparent bodies, with generalisation and extension of the foundations of Neumann's method, by M. Réthy.-Thermal theory of development of electricity, by J. L. Hoorweg.-On the behaviour of electricity in gases, and especially in vacuum, by F. Narr.-Defence of the law of corresponding boiling temperatures, by U. Dïhring.-Equation of the state of atmospheric 